\section{¿Qué ocurre en la práctica clínica cuando se interrumpe el tratamiento antirretroviral?}

\section{Sr. Director:}

La interrupción estructurada del tratamiento antirretroviral podría considerarse el método más simple de terapia inmunomediada (1).

Otros objetivos para la introducción de la interrupción estructurada del tratamiento que tenían menor importancia al principio de la utilización de esta estrategia, serían el ahorro de medicación y la reducción de efectos secundarios y de gastos, han pasado a un primer lugar a medida que se han ido conociendo mejor los efectos secundarios a largo plazo de la medicación antirretroviral $(2,3)$.

Sin embargo, existen problemas importantes con la interrupción estructurada del tratamiento antirretroviral que pueden manifestarse a corto y largo plazo, así diversos estudios han mostrado descensos de CD4 a concentraciones basales en muy poco tiempo (4).

Actualmente se considera que los ensayos de interrupción de tratamiento antirretroviral han servido prácticamente para casi nada, aunque al menos se ha comprobado que no se habían desarrollado resistencias al menos en un plazo corto (5).

Otra situación bien diferente es la que comprende a los pacientes que comenzaron un tratamiento antirretroviral de gran actividad en una situación claramente mejor que lo que las actuales recomendaciones preconizan. Hay que recordar que actualmente se recomienda empezar el tratamiento cuando los CD4 sean inferiores a 350, independientemente de la carga viral y algunos incluso, retrasan el comienzo del tratamiento a unos niveles de CD4 cercanos a 200 células (5).

Nos parece interesante presentar nuestros resultados en un plazo de más de 2 años en un grupo de 6 pacientes a los que interrumpimos el tratamiento antirretroviral, por haberse iniciado el mismo con cifras de CD4 superior a 350 células, siguiendo los criterios del momento, fundamentalmente teniendo en cuenta la carga viral. Otros criterios que seguimos para la interrupción del tratamiento fueron que no hubiera presentado ningún problema relevante durante su evolución; la carga viral debía ser indetectable; el paciente debía haber mostrado una buena adherencia al tratamiento antirretroviral durante el seguimiento y además tenía que firmar un consentimiento informado aceptando la suspensión del tratamiento. Se continuaban efectuando revisiones periódicas cada 2-3 meses y se indicó que se reanudaría el mismo tratamiento antirretroviral que llevaba previamente si los CD4 descendían de 350 células o desarrollaba un evento definitorio de sida.

Caso 1. Mujer de 38 años, seropositiva al VIH en 1999, no ADVP. En octubre de 2000 se inició tratamiento antirretroviral con estavudina, didanosina y efavirenz, con CD4 de 490 células y carga viral de 38.300 copias. El tratamiento fue interrumpido en noviembre de 2002 con CD4 de 884 y carga vírica indetectable. En mayo de 2004 (17 meses de seguimiento) los CD4 eran de 732 y la carga vírica de 52.700 copias. Se perdió el seguimiento al cambiarse de domicilio.

Caso 2. Mujer de 43 años. VIH positivo en 1992. Era conyuge de un paciente VIH positivo fallecido. No ADVP. Se inició el tratamiento en abril de 1998 con CD4 de 366, sin disponer por entonces de carga viral en nuestro hospital. Inicialmente con zidovudina y lamivudina, añadiendo posteriormente nelfinavir. El tratamiento fue interrumpido en diciembre de 2002, con CD4 de 1044 y carga viral indetectable. En marzo de 2005 (27 meses de seguimiento), los CD4 eran de 651 y la carga viral de 133.000 copias y sigue sin tratamiento antirretroviral.

Caso 3. Varón de 37 años. VIH positivo desde 1997. ADVP. Hepatopatía crónica por el virus de la hepatitis C. Iniciado el tratamiento con zidovudina y zalcitabina en octubre de 1997 con CD4 de 353 y carga viral no disponible en ese momento en nuestro centro. En enero de 2003 los CD4 eran de 574 y la carga viral no detec- tada, interrumpiéndose el tratamiento antirretroviral. En septiembre de 2004 (21 meses de seguimiento), los CD4 eran de 354 y la carga viral de 8.400 copias. Falleció en octubre de 2004 de una insuficiencia hepática terminal, sin haberse reiniciado el tratamiento.

Caso 4. Varón de 22 años. VIH positivo desde el 2000. ADVP. En mayo de 2000, los CD4 eran de 487 y la carga viral de 24.100 copias, iniciándose el tratamiento antirretroviral con didanosina, estavudina y nevirapina. En diciembre de 2002, los CD4 eran de 950 y la carga viral indetectable, interrumpiéndose el tratamiento antirretroviral. Además el paciente tenía una depresión mayor. En marzo de 2005 (28 meses de seguimiento), los CD4 eran de 1090 y la carga viral de 5420 copias y sigue actualmente sin tratamiento.

Caso 5. Varón de 43 años. VIH positivo desde 1987. ADVP. En 1998 se inició tratamiento antirretroviral con estavudina, didanosina y ritonavir, posteriormente sustituido por nevirapina, por CD4 de 404 y carga viral de 87.708 copias. En febrero de 2003, los CD4 eran de 868 y la carga viral era indetectable, interrumpiéndose el tratamiento antirretroviral. En agosto de 2004( seguimiento de 18 meses), se reinició el mismo tratamiento por CD4 de 308 y carga viral de 107.00 copias. En marzo de 2005, los CD4 eran de 425 y la carga viral indetectable.

Caso 6. Varón de 35 años. VIH positivo desde el 2001. ADVP. Se inició el tratamiento en marzo de 2001 con zidovudina, lamivudina y abacavir por CD4 de 496 y carga viral de 168.000 copias. Se interrumpió el tratamiento en enero de 2003 con CD4 de 709 y carga viral indetectable. En marzo de 2005 (27 meses de seguimiento), los CD4 eran de 603 y la carga viral de 115.00 copias y sigue actualmente sin tratamiento.

Como resumen, de los 6 pacientes incluidos en el estudio, tras un seguimiento medio de 23 meses (17-28 meses), tres pacientes continúan sin tratamiento antirretroviral (seguimiento medio de 27 meses), hubo una pérdida de seguimiento por cambio de domicilio y un fallecimiento por insuficiencia hepática terminal, sin haber precisado reiniciar el tratamiento.

El único paciente en el que se reinició el tratamiento antirretroviral tras una interrupción de 18 meses, se encuentra actualmente con carga viral indetectable, por lo que parece apoyar la idea de que no se generan resistencias, al menos a corto plazo, tras la interrupción del tratamiento antirretroviral.

Resulta evidente el ahorro de efectos secundarios y económico que se ha conseguido tras la interrupción del tratamiento, sin evidenciarse complicaciones serias, por lo que la interrupción del tratamiento en los muchos casos en los que se inició siguiendo unos criterios diferentes a los que actualmente se aplican puede resultar una opción interesante para nuestros enfermos.

\section{F. Marcos Sánchez, I. Albo Castaño, D. Joya Seijo, P. del} Valle Loarte, M. J. Martín Barranco

Servicio de Medicina Interna. Hospital Nuestra Señora del Prado. Talavera de la Reina, Toledo

1. Montaner L. Structured treatment interruptions to control HIV-1 and limit drug exposure. Trends Immunol 2001; 22: 92-6.

2. Martínez E, Mocroft A, García-Viejo M, Pérez-Cuevas J, Blanco J, Mallolas J, et al. A prospective cohort study on the risk for lipodystrophy in HIV-1 infected patients treated with protease inhibitor-containing regimens. Lancet 2001; 357: 592-8.

3. Dybul M, Chun TW, Yoder C, Hidalgo B, Belson M, Hertogs K, et al. Short-cycle structured treatment of chronic HIV infection with higly active antiretroviral therapy: effects on virologic, immunologic and toxicity parameters. Proc Natl Acad Sci 2001; 98: 15161-66.

4. García F, Plana M, Ortiz GM, Borhoeffer S, Soriano A, Vidal C, et al. The virological and immunological consequences of structured treatment interruptions in chronic HIV-1 infection. AIDS 2001; 15: 19-27.

5. García F, Clotet B, Moreno S, López Bernardo de Quirós JC, Gatell JM. Interrupciones del tratamiento en la práctica clínica. Enferm Infecc Microbiol Clin 2002; 20 (Supl 2): 68-73. 